\title{
REPRESENTAÇÕES DE PROFESSORES DO CURSO DE LETRAS SOBRE O DICIONÁRIO
}

\author{
Mikaeli Cristina Macêdo Costa (UERN) \\ José Válter Rebouças (UERN) \\ Antônio Luciano Pontes (UERN)
}

Resumo: Este trabalho contempla como finalidade principal analisar a representação dos professores do curso de Letras das três habilitações do CAMEAM-UERN sobre o dicionário, bem como discutir sobre o lugar destinado a esse recurso lexicográfico no Programa Geral do Componente Curricular (PGCC). O contexto escolhido para a realização desta pesquisa foi a UERN, tendo como corpus para análise os programas das disciplinas de Metodologias I (Espanhol e Inglês) e Didática da Língua Portuguesa e o material discursivo obtido através de um questionário realizado com três professores que as ministraram. A partir desse percurso investigativo, percebeu-se que os resultados da análise apontaram que os PGCC de Metodologia I dos cursos de graduação em Letras (Espanhol e Inglês) e o de Didática da Língua Portuguesa da UERN não reconhecem o dicionário como ferramenta didática a ser trabalhada numa disciplina de formação de futuros professores de língua, uma vez que essas disciplinas não abordam propostas que favoreçam a incorporação desse recurso de imprescindível importância para o ensino de língua nos conteúdos de seus programas.

Palavras-chave: Representação, Professores do curso de Letras, Dicionário, Programa Geral do Componente Curricular.

Abstract: This work has as its primary purpose to analyze the representation of Linguistics professors from three languages from CAMEAM-UERN about the dictionary, as well as to discuss the place intended for that lexicographical tool in the General Program of the Disciplines. The context chosen for this research was the UERN, which the corpus were programs of the following disciplines: Methodologies I (Spanish and English) and Didactics of Portuguese and discursive material obtained through a questionnaire conducted with three teachers who ministered them. The results of that analysis indicated that the Programs of Methodology I of graduation courses in Languages (Spanish and English) and the Didactics of Portuguese Language do not 
recognize the dictionary as a teaching tool to be deployed in a course of teachers education of languages, since these disciplines do not address proposals that support the incorporation of this tool which has fundamental importance to the teaching of language in the content of their programs.

Keywords: Representation, Linguistics Professors, Dictionary, General Program of Disciplines.

\section{PALAVRAS INICIAIS}

Compreendendo a importância do dicionário enquanto ferramenta didática indispensável no ensino de língua, este trabalho pretende analisar a representação dos professores do curso de Letras do CAMEAM-UERN, com o intuito de fazer um estudo sobre os sentidos que esses docentes atribuem a esse material, bem como o papel a ele destinado no processo de formação acadêmica.

Tomando como base o fato de o PGCC ser o primeiro contato ou diálogo entre o professor e o aluno, parte-se da análise desse instrumento para verificar se o docente de Letras, ao elaborar o programa de sua disciplina, contempla o dicionário enquanto ferramenta didática que contribui para o processo de ensino e aprendizagem de línguas. Nesse contexto, compreende-se que o professor dessa disciplina deve conduzir o graduando, futuro profissional da educação, para uma reflexão acerca do papel que esse recurso desempenha nas aulas de línguas, ressaltando que 
essa proposta deve ser reforçada em todas as disciplinas direcionadas para a formação de professores seja de língua materna ou de língua estrangeira, já que no decorrer das unidades são desenvolvidos conteúdos envolvendo formação e significação de palavras, produção textual, gêneros do discurso, classes gramaticais entre outros, de modo que o dicionário pode contribuir para a aprendizagem desses conteúdos.

Considerando esse pressuposto, ressalta-se a necessidade de formação sobre o uso do dicionário nos cursos de licenciatura em línguas a fim de os futuros professores orientarem, de forma significativa, seus alunos a utilizaremno nas práticas educativas realizadas em sala de aula. Pois, conforme Pontes (2009, p.105):

Já foi constatado, através de pesquisas em sala de aula, que o aluno se frustra diante do dicionário por não ter sido antes "treinado" para usá-lo adequadamente. Essa situação justifica-se principalmente pelo fato de o professor não se formar bem teórica e metodologicamente para o trabalho com o dicionário em sala de aula. (Idem, 2009, p.105)

Partindo dessa premissa, é possível considerar que um dos motivos que podem justificar essa dificuldade do docente em usar e selecionar o melhor dicionário para o aluno na sala 
de aula seja a inexistência de uma disciplina específica na área de lexicografia pedagógica incluída na grade curricular dos cursos de formação de professores.

Diante dessa inquietação, surge a necessidade de fazer um estudo sobre a concepção desses professores sobre o objeto de representação, o dicionário, com intuito de investigar no âmbito de um curso superior, especificamente o de Letras do CAMEAMUERN, a forma de abordagem desse recurso em disciplinas de formação. Para tanto, os sujeitos da pesquisa foram professores do curso de Letras das três habilitações da UERN, Campus de Pau dos Ferros. Com base na grade curricular dos três cursos de Letras, foram contempladas, dentre as disciplinas ofertadas, as de Metodologia I do curso de Espanhol e Inglês e Didática da Língua Portuguesa (do curso de Letras com habilitação em Língua Portuguesa) com o propósito de investigar, além da representação desses professores, o espaço reservado para se discutir acerca da relevância dessa ferramenta para o ensino de línguas. Desse modo, considerou-se como corpus de análise o material discursivo proveniente dos questionários e os PGCC, a fim de descrever e analisar a forma como se organiza o programa desses componentes curriculares.

Depois de analisar os PGCC, constatou-se que nem todos os professores contemplam o dicionário em seu plano de 
ação didática. Por isso, ficou evidente a necessidade de compreender como se processou a formação desses docentes e se eles, apesar de não o mencionarem no PGCC, trabalham com essa ferramenta de ensino e orientam os alunos com relação à utilização correta desse recurso. Dando sequência ao trabalho, foi aplicado um questionário com os professores da UERN, os quais ministram essas determinadas disciplinas, com o intuito de se entender melhor a organização desses programas e, especificamente, qual a representação desses professores sobre o dicionário.

\section{REPRESENTAÇÕES SOCIAIS: BUSCANDO DEFINIÇÕES}

A Teoria das Representações Sociais (TRS) proposta por Moscovici (1976), na década de 60, consiste em uma forma de conhecimento teórico e social, ao mesmo tempo em que busca investigar como os indivíduos em suas interações diárias constroem suas representações sobre as coisas.

Moscovici (1976), em seus estudos iniciais, buscou investigar e reformular o conceito de representações coletivas de acordo com a visão de Durkheim, redefinindo o termo "coletivo" por "social", com o propósito de explicar como o individual se constrói no social e vice-versa, proporcionando assim a dinamicidade das representações sociais (doravante RS). 
A partir dessa concepção, os indivíduos passam a ter um lugar especial, pois, enquanto sujeitos do discurso, fazem uso da linguagem, principal instrumento da interação e comunicação humana, para interagir e representar o mundo em geral com o intuito de compreender a realidade.

Assim, a TRS procura entender como as pessoas se tornam conhecedoras de uma realidade social, bem como ocorre o processo de significação dessa realidade e o motivo de sua transformação nesse contexto. Além disso, essa teoria procura investigar como os indivíduos ou grupo social, ao depararem com uma situação ou informação, constroem significados e representações sobre esse conhecimento, inicialmente desconhecido ou pouco familiar.

Convém ressaltar também que, segundo Moscovici (1976), uma RS é construída por meio de duas atividades ao nível da mente: a objetivação e a ancoragem. Essas atividades, por sua vez, recebem influências do contexto social em que membros de um determinado grupo social estão inseridos. Partindo dessa premissa, enfatiza-se a relevância desse contexto na formação e organização das representações.

Moscovici (1976, p.26) define representação social como "uma modalidade de conhecimento particular que tem por função a elaboração de comportamentos e a comunicação 
entre indivíduos". Esse conhecimento é popular em virtude de essa representação ser oriunda do senso comum e por ser construída socialmente na vida cotidiana dos indivíduos que buscam entender e agir sobre a realidade. Logo, a RS exerce a função orientacional no sentido de que orienta os indivíduos em suas práticas sociais.

A esse respeito, Alexandre (2004, p.127) destaca que as RS são consideradas uma modalidade particular porque “não é todo 'conhecimento' que pode ser considerado representação social, mas somente aquele que faz parte da vida cotidiana das pessoas, através do senso comum, que é elaborado socialmente e que funciona no sentido de interpretar, pensar e agir sobre a realidade".

Uma das colaboradoras da Teoria das Representações Sociais, Jodelet (2001) em sua pesquisa sobre as RS sobre a loucura, busca dar continuidade ao estudo moscoviciano a partir de uma perspectiva dimensional, definindo as representações como "uma forma de conhecimento, socialmente elaborado e partilhado, com um objetivo prático e que contribui para a construção de uma realidade comum a um conjunto social" (JODELET, 2001, p.22). Esse conhecimento, por sua vez, é construído através de interações diárias de que os indivíduos participam em busca 
de entender a realidade. Ainda se tratando dessa questão, a autora ressalta que:

Sempre necessitamos saber o que temos a ver com o mundo que nos cerca. É necessário ajustar-se, conduzir-se, localizar-se física ou intelectualmente, identificar e resolver problemas que ele põe. Eis porquê construímos representações. E, da mesma forma que, ante as coisas, pessoas, eventos ou ideias, não somos equipados apenas com automatismos, igualmente não somos isolados em um vazio social: compartilhamos o mundo com outros, neles nos apoiamos - às vezes convergindo; outras, divergindo - para o compreender, o gerenciar ou o afrontar. Por isso as representações são sociais e são tão importantes na vida cotidiana. Elas nos guiam na maneira de nomear e definir em conjunto os diferentes aspectos de nossa realidade cotidiana, na maneira de interpretá-los, estatuí-los e, se for o caso, de tomar uma posição a respeito e defendê-la. (Idem, 2001, p.17).

Considerando essa perspectiva, não é possível entender o indivíduo como um ser isolado do mundo, pois faz parte da natureza humana a interação contínua com a sociedade, o ser humano sente a necessidade de compartilhar e construir conhecimentos e saberes com outras pessoas. Por isso, as representações sociais são tão essenciais, pois é através delas que os indivíduos buscam entender a realidade por meio de 
suas interações em contextos sociais. Essa é a dinâmica da vida em sociedade, que orienta as pessoas a viverem e a agirem em grupos.

Os indivíduos, enquanto sujeitos sociais, estão sempre em busca de conhecimentos que guiem suas ações nas interações comunicativas, com o propósito de estarem sempre conectados com ideologias, valores históricos e culturais do mundo no qual estão inseridos.

\section{DICIONÁRIO: OBJETO DE REPRESENTAÇÃO}

$\mathrm{Na}$ presente investigação, elege-se o dicionário como objeto de representação partindo da ideia de que uma RS é sempre de alguém (um grupo social) sobre alguma coisa (o objeto de representação), enfatizando a "relevância cultural" e a "espessura social" (SÁ, 1998) como condições para que determinado elemento do mundo possa ser tomado como um objeto de representação social.

Sendo assim, pressupõe-se que o dicionário é um material de referência que tem por objetivo fornecer informações e significados de determinadas palavras de uma língua. Mas, além de informações, existem também representações (crenças, valores e ideologias) que marcam o significado de cada verbete de acordo com o contexto que ocupa na sociedade. 
Nessa conjuntura, destaca-se a partir das palavras de Sá (1998) a "relevância cultural" e a "espessura social" do dicionário de E/LE (espanhol como língua estrangeira) como objeto de representação na medida em que esse instrumento de ensino constitui material didático ou de apoio bastante utilizado para facilitar a aprendizagem de uma língua estrangeira. A esse respeito, Biderman (2001, p. 75) faz a seguinte consideração:

Dado o papel do dicionário em relação à norma social, por registrar a linguagem aceita e valorizada na comunidade dos falantes e também por ser o depositário do acervo lexical da cultura, ele é uma referência básica para uma comunidade. Por isso o dicionário é um instrumento indispensável e imprescindível na fixação do léxico de uma língua e ferramenta fundamental na consolidação de uma língua escrita e literária.

Além disso, Krieger (1993, Apud ARAÚJO, 2007, p.33) ressalta que há uma ligação do dicionário com a cultura de um povo, conceituando-o como um texto que expõe a cultura através das unidades lexicais que o compõem, expondo, assim, um universo semântico cultural. Já, na visão de Coroa (2011, p.63) "o dicionário é mais do que uma forma de nomear e classificar as coisas do mundo: é um apoio para a construção de nossa rede de conhecimentos linguísticos". 
Vale assinalar que o dicionário sempre foi considerado uma ferramenta didática de grande relevância na aprendizagem tanto de língua materna como de línguas estrangeiras, uma vez que, logo nos primeiros anos de estudos, o professor já solicita aos alunos que busquem no dicionário informações e significados com relação à ortografia de determinadas palavras. No entanto, na condição de pesquisadores, o que se torna preocupante é se de fato esses alunos, futuros professores de língua, estão sendo orientados sobre o uso do dicionário de maneira correta.

\section{METODOLOGIA}

À proporção que esta pesquisa propôs- se a analisar a representação dos professores de Letras das três habilitações do CAMEAM-UERN, bem como o lugar que o dicionário ocupa nas disciplinas de formação em língua materna e estrangeiras (inglês e espanhol), foi necessário, primeiramente, escolher o universo a ser contemplado. Pensou-se, então, em fazer uma investigação nas disciplinas de Metodologia I, referente às habilitações de Língua Espanhola e Língua Inglesa e Didática da Língua Portuguesa, com o intuito de contribuir para o aperfeiçoamento dos programas dessas disciplinas. Portanto, o locus foi a própria UERN e, em especial, o curso de Letras das três habilitações. 
Neste estudo, buscou-se analisar, além da representação de professores acerca do dicionário, indagações como: De que maneira esse recurso é empregado em disciplinas de formação em curso de licenciatura em Letras? Será que nessas disciplinas esse material é concebido como importante ferramenta didática? Essas questões foram avaliadas na medida em que os PGCC e o material discursivo proveniente dos questionários estavam sendo analisados.

Como o propósito foi verificar a representação dos professores de Letras acerca do dicionário e se esse material era contemplado durante a proposta de ensino, o foco foi direcionado para os conteúdos programáticos a fim de investigar o lugar que essa ferramenta ocupa em sala de aula, sendo o questionário alvo das análises das representações que os docentes atribuem ou constroem em relação a esse material didático.

Os sujeitos da pesquisa foram três professores do curso de Letras do CAMEAM-UERN das três habilitações (um de cada habilitação), ressaltando que dois são mestres em Letras e um especialista, dois são docentes provisórios e um efetivo.

Com relação à carga horária das disciplinas, existem distinções: Didática da Língua Portuguesa tem 120 horas, Metodologia I do Espanhol são 40 horas e Metodologia I 
do Inglês, 90 horas, sendo que todas são pré-requisitos de Didática Geral.

\section{DICIONÁRIO: PGCC E AS REPRESENTAÇÕES DE PROFESSORES}

Nesta seção, pretende-se fazer uma análise dos PGCC das disciplinas de Metodologia I do curso de língua espanhola e língua inglesa e Didática da língua Portuguesa, a fim de se investigar o lugar destinado ao material didático (dicionário). Posteriormente, será feito um estudo acerca das significações (representações) que professores de Letras do CAMEAMUERN constroem sobre o referido objeto de representação, com o intuito de compreender se essas concepções influenciam na maneira como esses docentes contemplam ou abordam essa ferramenta didática em suas aulas.

Considerando o dicionário como um material promissor para a prática pedagógica, abordou-se nesta pesquisa sobre os conteúdos programáticos trabalhados nos programas de ensino das disciplinas mencionadas anteriormente. Seguem esses conteúdos das três habilitações do curso de Letras: 
IV. CONTEÚDO PROGRAMÁTICO

\section{UNIDADE 1 - PRESSUPOSTOS PARA O ENSINO DE LÍNGUA} MATERNA

1.1 Concepções de linguagem, objetivos e tipos de ensino de língua materna;

1.2 Ensino de língua - algumas reflexões teóricas;

1.3 Gêneros Textuais e ensino de língua materna;

1.4 O plano de aula: noções teórico-práticas.

\section{UNIDADE 2 - AS PRÁTICAS DE LINGUAGEM E O ENSINO DE LÍNGUA PORTUGUESA}

2.1 Unidades básicas do ensino de Língua Portuguesa: a leitura, a produção de textos e a análise linguística;

2.2 A leitura da literatura na sala de aula;

2.3 O ensino de português e as novas linguagens mediadas pelas TICs;

2.4 O livro didático e o ensino de português

2.5 A linguagem oral como objeto de ensino

\section{UNIDADE 3 - MODELOS DIDÁTICOS PARA O ENSINO DE LÍNGUAS}

3.1. Procedimentos teórico-práticos para o ensino de português: o trabalho com a leitura, a escrita e a gramática, em escolas do Ensino Fundamental e Médio.

Figura 1 (PGCC de Didática e Língua Portuguesa) 


\section{CONTEÚDOS PROGRAMÁTICOS}

- Introducción/Texto de Rubem Braga - Qualidade total em Educação - Ellos hablan potuñol. E agora?

- Fundamentos de lingüística aplicada

- Metodología: Como se adquiere la lengua materna - La lengua materna y las lenguas no nativas/Qué es la interlengua (IL) - Las teorías de Adquisición y la didáctica de una lengua extranjera - Breve historia de la enseñanza de idiomas/Comparación y evaluación de los métodos: algunas sugerencias

- O difícil dialogo entre os gêneros textuais literários e o ensinoaprendizagem de $\mathrm{E} / \mathrm{LE}$

- Guia de livros didáticos.

Figura 2 (PGCC de Metodologia I do Espanhol)

\section{CONTEÚDO}

- HARMER, J. The Practice of the English Language Teaching. Essex: Longman, 2001.

- The silent way (apresentação em vídeo)

- Desuggestopedia (apresentação em vídeo)

- Community language learning (apresentação em vídeo)

- Total Physical Response (apresentação em vídeo) e Reflexive Teaching (MACKEY, S. L. O professor reflexive: Guia para investigação do comportamento em sala de aula. São Paulo: Specila Book Services Livraria, 2003)

Figura 3 (PGCC de Metodologia I do Inglês) 
Conforme se pode perceber, os conteúdos programáticos das três disciplinas apresentadas acima não contemplam o dicionário enquanto material didático indispensável no ensino de línguas. Diante dessa constatação, a respeito da ausência desse material em plano de ação de didática em curso de formação de futuros professores de línguas, surge a necessidade de se estudar sobre as representações dos professores que ministram as disciplinas de Metodologia e Didática do curso de Letras acerca dessa ferramenta de ensino, com o intuito de conhecer os posicionamentos desses sujeitos sobre esse objeto de representação e se eles, apesar de não o contemplarem em seus programas de ensino, trabalham com esse recurso e orientam seus alunos sobre a forma correta de utilizá-lo.

Para a constituição da análise dessa representação, utilizou-se a técnica de aplicação de questionário, sendo solicitado aos sujeitos da pesquisa (professores) que respondessem a sete (7) questões referentes ao objeto de representação "dicionário", visando a conhecer os temas que compõem as RS desses profissionais. No momento em que foram indagados se trabalhavam com o dicionário em sala de aula, os docentes de língua estrangeira salientam que:

Sim, sempre utilizo durante as aulas e também durante as provas. (Professor (a) de Metodologia I do inglês) 
Sim, utilizo. (Professor (a) de Metodologia I do espanhol)

Já a professora de Didática da Língua Portuguesa ressaltou que:

Não costumo usar pelo caráter das atividades propostas. Porém, costumo orientar os alunos sobre o uso desse instrumento, levando-os a perceber que, muitas vezes, é preciso recorrer ao dicionário para compreender alguns sentidos dos textos, desde que adequando esses sentidos aos contextos. (Professor (a) de Didática da Língua Portuguesa)

Diante dessa constatação, deve-se considerar que, apesar de não mencionarem essa ferramenta de ensino em seus planos de ações didáticas, os professores de língua estrangeira abordam o uso desse material didático no contexto da sala de aula.

Com relação à orientação sobre o uso do dicionário, ao serem indagados se orientavam seus alunos, responderam que:

Não oriento de forma sistemática. É uma orientação mais no sentido de dialogar sobre a necessidade, em alguns casos, do uso do dicionário. Uma orientação mais sistemática deve ser através do próprio uso do dicionário em sala de aula e isso não ocorre. (Professor (a) de Didática da Língua Portuguesa)

Oriento, sim. (Professor (a) de Metodologia I do inglês) 
Sim, é importante, pois permite esclarecer dúvidas e aprimorar seus conhecimentos. Até porque são alunos de língua estrangeira. (Professor (a) de Metodologia I do espanhol)

Então, diante desses posicionamentos, compreende-se que os professores orientam seus alunos sobre o uso desse recurso didático. No caso de língua portuguesa, o docente salienta que orienta à proporção que sente a necessidade em algumas situações envolvendo o uso do dicionário. No caso dos outros professores, alegam que orientam por se tratar de formação de futuros profissionais de língua estrangeira.

Frente a esse resultado, percebe-se a representação do dicionário como material didático que auxilia no processo de ensino e aprendizagem de uma segunda língua. Mas, é preciso ressaltar que esses docentes não são capacitados para orientar corretamente sobre o uso adequado do dicionário de acordo com o contexto e a realidade do aluno. Desse modo, Pontes (2009, p.13), enfatiza que:

Torna-se necessário qualificar professores para utilizarem dicionários em sala de aula, pois o que se tem hoje são profissionais sem um preparo adequado para orientar os alunos com relação à leitura ou consulta de dicionários. Coloca-se, então, a formação do professor sobre lexicografia escolar como algo muito importante, pois lhe 
cabem várias tarefas relativas a essa área do conhecimento linguístico.

Partindo dessa premissa, Gregório Salvador lapud HERNÁNDEZ, 1989, p.35), afirma que: "uma das principais tarefas do professor de língua consiste em manusear todos os tipos de dicionários, ilustrar e informar sobre eles, criticálos, assinalar as vantagens e inconveniências, guiar o aluno no oceano lexicográfico". Sendo assim, faz-se necessária uma boa formação dos professores na área de lexicografia para poder alcançar objetivos significativos nas aulas com o uso do dicionário.

Em relação ao posicionamento desses professores sobre o dicionário, ao serem indagados sobre como veem essa obra lexicográfica, se como ferramenta didática ou apenas como material de consulta, eles afirmam que:

Depende do contexto de uso. Em alguns casos ele pode ser usado como obra de consulta. Em outros casos, na grande maioria das vezes, ele é uma ferramenta didática que auxilia o trabalho com a linguagem. (Professor (a) de Didática da Língua Portuguesa)

Ele funciona como os dois, já que é ferramenta didática para se consultar e trabalhar com o léxico na sua forma total, tratando-se de um dicionário mais completo. (Professor (a) de Metodologia I do inglês) 
Relativo, vai depender do objetivo da aula a ser ministrada. Por exemplo: quando utilizamos um dicionário para tradução, nesse caso utilizamos como uma obra de consulta que serve para tirar dúvidas... etc. no trabalho com textos literários ou de línguas, usamos como ferramenta didática. (Professor (a) de Metodologia I do espanhol)

Como pode ser observado, o dicionário exerce várias funções, sendo que cada uma vai depender do contexto de uso. Os professores afirmam que, de acordo com a situação de uso e objetivo de uma determinada aula, esse material poderá ser uma obra de consulta ou uma ferramenta didática indispensável no processo de aprendizagem.

Do exposto, é possível concluir que há mais de uma representação desses professores sobre o dicionário, podendo exercer diferentes funções mediante cada contexto. Diante dessas considerações e de uma variedade de obras lexicográficas, é oportuno acrescentar que os alunos/ consulentes, no caso, futuros docentes de línguas deverão selecionar aquela que se ajuste às suas necessidades em cada momento de uso. Para isso, urge ressaltar a importância da formação lexicográfica em cursos de licenciatura em Letras a fim de orientar e indicar o melhor dicionário para cada clientela e as variadas possibilidades de se explorar o potencial desse recurso na prática docente. 
Em relação à finalidade do uso desse instrumento lexicográfico, os professores salientaram que, na maioria das vezes, solicitam a seus alunos o uso desse recurso para verificar o significado de alguma palavra, o que acaba reforçando a representação do dicionário como uma obra de consulta.

Ao serem indagados sobre os critérios que utilizam no momento de escolherem o melhor dicionário para seus alunos, os docentes ressaltam que:

Não uso critérios para escolha, já que não direciono o uso de um dicionário específico. O dicionário, assim como a gramática, constituem instrumentos de aprendizagem que já devem ser do conhecimento do aluno antes mesmo do ingresso no ensino superior. Nesse nível de ensino, os alunos devem ter autonomia para escolher suas ferramentas de consulta e de aprendizagem. Penso que até os textos que levamos para a sala de aula devem ser apenas um suporte, mas, é dever do aluno pesquisar, buscar outros textos e outros conhecimentos, já que os paradigmas de ensino são outros e colocam o aluno no centro do processo de aprendizagem. (Professor (a) de Didática da Língua Portuguesa)

Sempre escolho os melhores internacionais; respeitando a limitação linguística e financeira dos meus alunos. (Professor (a) de Metodologia I do inglês) 
Nível de estudo (contexto), finalidade do curso e realidade do aluno. (Professor (a) de Metodologia I do espanhol)

Como base nos argumentos dos docentes, fica evidente que cada um apresenta um critério distinto, o de Didática da Língua Portuguesa afirma que não utiliza nenhum critério, pois, na sua concepção, o aluno, antes mesmo de ingressar em um curso superior, deve ter o conhecimento sobre dicionário e gramática, por se tratar de materiais de aprendizagem, enfatizando assim, o exercício da autonomia do discente ao eleger suas ferramentas de estudo. O segundo professor prioriza os melhores internacionais, de acordo com a realidade financeira dos alunos. Já, o terceiro educador escolhe o melhor dicionário a partir da finalidade do curso, ou seja, do contexto e realidade do estudante.

Diante desses depoimentos, acentua-se a relevância da formação lexicográfica a fim de esses docentes poderem indicar e orientar a melhor obra lexicográfica de acordo com o objetivo de cada aula. Sem falar, que esses educadores afirmaram que, quem deve ensinar aos alunos a manusear o dicionário são eles próprios no contexto da sala de aula. Então, surge a questão: Como os professores, sem formação lexicográfica, vão ensinar seus alunos, futuros profissionais de línguas, sobre o uso do dicionário? Partindo dessa 
premissa, verifica-se a necessidade de "qualificar professores para utilizarem dicionários em sala de aula, pois o que se tem hoje são profissionais sem um preparo adequado para orientar os alunos com relação à leitura ou consulta de dicionários" (PONTES, 2009, p.13). Dessa forma, o professor terá consciência do potencial didático do dicionário, da capacidade que tem de ampliar o conhecimento do léxico de uma língua, bem como de auxiliar no desenvolvimento das atividades de leitura e produção de textos dos alunos.

\section{PALAVRAS FINAIS}

A presente pesquisa buscou analisar a representação dos professores de Letras das três habilitações do CAMEAM-UERN sobre o dicionário e o lugar destinado a esse material nos programas de ações didáticas das disciplinas: Metodologia I (Espanhol e Inglês) e Didática da Língua Portuguesa.

Partindo dessa conjuntura, ao serem analisados os PGCC, foi possível perceber que os professores não contemplam em seu plano de ensino o dicionário como ferramenta didática, que deve ser abordado e orientado sobre seu uso em cursos de licenciatura em línguas. Dessa forma, ratifica-se sobre a importância de uma disciplina voltada à lexicografia pedagógica para que alunos, futuros docentes de línguas, possam ter em sua formação acadêmica um 
espaço dedicado à orientação e capacitação sobre o uso de dicionário em sala de aula.

As representações que norteiam os professores que ministram as disciplinas, mencionadas anteriormente, a respeito do dicionário é que se apresenta como uma ferramenta didática que além de ser uma obra de consulta pode exercer outras funções dependendo do objetivo da aula.

A partir dessa percepção, este trabalho pretende contribuir para uma reflexão acerca dos programas das três disciplinas: Didática da Língua Portuguesa e Metodologia I do (Espanhol e Inglês) da UERN, propondo uma nova perspectiva para os seus objetivos e para os seus conteúdos, disseminando, assim, uma política de inserção do dicionário às práticas docentes. Para tanto, fomenta-se sobre a necessidade de qualificar professores para orientarem seus alunos em relação às possibilidades de uso desse material didático.

Além disso, não se poderia deixar de mencionar a contribuição dessa investigação ao estado de arte do dicionário como componente das disciplinas de formação de professores, neste caso, considerando as três habilitações do curso de Letras do CAMEAM-UERN.

Portanto, espera-se que o presente trabalho sirva para suscitar outras reflexões e discussões acerca do uso do 
dicionário, tendo em vista o potencial que representa à prática pedagógica, favorecendo a construção de competências necessárias ao desenvolvimento integral dos alunos.

\section{REFERÊNCIAS}

ALEXANDRE, M. (2004) Representação social: uma genealogia do conceito. Comum, Rio de Janeiro - v.10 - n²3 - p. 122-138.

ARAÚJO, E. M. V. M. (2007) O dicionario para aprendizes em sala de aula: uma ferrramenta de ensino e aprendizagem. Dissertacão de mestrado. Universidade Estadual do Ceará: Fortaleza.

BIDERMAN, T. C. (2001) As ciências do léxico. In: OLIVEIRA, A. M. P. P.; ISQUERDO, A. N. As ciências do léxico: lexicologia, lexicografia, terminologia. 2. ed. Campo Grande: UFMS, p. 13-22.

COROA, M. L. (2011) Para que serve um dicionário?. In: CARVALHO, O. L. de S. e BAGNO, M. (orgs.). Dicionários escolares: políticas, formas \& usos. São Paulo: Parábola Editorial. p. 61-72.

HERNÁNDEZ, H. (1989) Los diccionarios de orientación escolar: contribución al estudio de la lexicografía monolingue española. Tubingen: Max Niemeyer Verlag.

JODELET, D. (2001) (Org.). As Representações Sociais. Rio de Janeiro: EdUERJ.

MOSCOVICl, S. (1976) A representação social da Psicanálise. Rio de Janeiro: Zahar Editores.

PONTES, A. L. (2009) Dicionário para uso escolar: o que é e como se lê. Fortaleza: EDUECE.

PONTES, A.L.; SANTIAGO, M. S. (2009) Crenças de professores sobre o papel do dicionário no ensino de língua portuguesa. In: COSTA DOS SANTOS, F. J. (Org.). Letras plurais: crenças e metodologias do ensino de línguas. Rio de Janeiro: Câmara Brasileira de Jovens Escritores. p. 105-123. SÁ, C. P. (1998) A construção do objeto de pesquisa em representações sociais. Rio de Janeiro: EdUERJ. 
Mikaeli Cristina Macêdo Costa é mestranda pelo Programa de PósGraduação em Letras pela Universidade do Estado do Rio Grande do Norte (PPGL/UERN). Bolsista CAPES/UERN. Pesquisadora do Grupo de Pesquisas e Estudos Aplicados em Línguas Estrangeiras (EALE) da Universidade do Estado do Rio Grande do Norte (UERN).

José Válter Rebouças é mestrando pelo Programa de Pós-Graduação em Letras da Universidade do Estado do Rio Grande do Norte (PPGL-UERN). Professor de Língua Portuguesa do Ensino Fundamental e Médio.

Antônio Luciano Pontes é doutor em Letras pela UNESP. Professor titular do Programa de Pós-Graduação em Letras da Universidade do Estado do Rio Grande do Norte (PPGL/UERN). Contato: pontes321@hotmail.com 